\title{
LAUNDRY WASHING MACHINE FOR CONSUMPTION OF CLOTHING, WATER AND ENERGY IN EGYPT
}

\author{
Zeinab EINashar ${ }^{1}$, Omar Cherkaoui ${ }^{2}$, Zlatin Zlatev ${ }^{3}$, ElSayed EINashar ${ }^{4}$ \\ ${ }^{1}$ Faculty of Arts, Department of English, Kaferelsheikh University, Egypt. \\ ${ }^{2}$ ESITH, Casablanca Prefecture, Morocco \\ ${ }^{3}$ Faculty of Technics and Technologies, Trakia University, Bulgaria \\ ${ }^{4}$ Faculty of Specific Education, Kaferelsheikh University, Egypt, e-mail: Smartex@kfs.edu.eg
}

\begin{abstract}
Consumption of clothing, water and energy by washing laundry is one of the most widespread housework in the Egypt. Today, washing machines do this work in many private households, using water, energy, chemical substances, and process time. Although energy efficiency is in the focus of many regulations which have already achieved significant improvements, the question remains, how relevant these processes are in terms of the absolute impact on resources and whether there are possibilities to improve even further by looking abroad. This survey, which is based on published data, compares the energy and water consumption for automatic laundry washing in an average private household with the total energy and water consumption of private households. Only little data are available on resource consumption for laundry washing based on in-use measurements are hard to obtain. But although some of the data in this report are poor, this is the first work that tries to elucidate the contribution of automatic laundry washing to the total energy and water consumption of households in selected countries North Africa. The report estimates the resource consumption of roughly about 37.72 Million only household washing machines in five countries (Egypt, Libya, Algeria Tunes, Morocco,) with about 188.6 Million people, which is about one third of the North Africa population. The results of this work show that laundry washing in private households is done with quite different amounts of energy and water in different parts of the North Africa both in absolute and relative comparison to the overall household consumption. But due to different consumer habits in dealing with the achieved washing performance in the different global regions, the best practice in washing laundry in a most sustainable way cannot be determined yet. Further research is needed to form a basis for a most sustainable development of resource consumption in Private households.
\end{abstract}

Keywords: laundry washing machine, energy saving, sustainability, water consumption.

\section{INTRODUCTION}

Washing "laundry" is popular in both men's and women's clothing because of its superior properties such as softness and ventilation, and other household textiles are one of the most widespread household works in some counties in North Africa such as "Egypt, lybia, tunsia, algaria, and moracoo ". so In Last decode the mechanical work was difficult, and in some parts of North Africa, it was still. Today, washing machines do this in many households in North Africa using water, energy, chemicals and processing time as resources. It is expected that the consumption of washing machines in different washing habits and actual application and types of washing machines vary significantly through the washing machine. While in the horizontal part of the machines, the bottom of the wash basin is filled only with water, and in the vertical axis machines, the entire basin is filled with water. Consequently, Horizontal axis machines consume much less water per wash cycle than vertical axis machines, while often machine operating without heating, especially in the five countries in North African, then the consuming far less energy per wash cycle than horizontal axis machines with integrated heating. But in fact, the main task of all types of washing machines is to provide clean and healthy laundry and maintain its value. This term specified. washing performance is not included in our work and an estimate of the different washing machine techniques along with energy consumption and water is not intended. For years, the state of art has been changed. The vertical axis machines are up to and including the present more prevalent in the five

IRTIIE Vol. 6, No. 2, 2018 ISSN 1314-8788 (print), ISSN 1314-8796 (online), doi: 10.15547/artte.2018.02.007 
countries in North African. But the share of horizontal axis machines in those markets is steadily increasing, for example, in $2007,22 \%$ of households used a horizontal axis machine in Australia. In 2005 , it was only $13 \%$. In some parts of the country, horizontal axis machines already achieve $50 \%$ of new sales of washing machines [1] in many times; horizontal axis devices have a temperature of not less than $30{ }^{\circ} \mathrm{C}$ which means that these devices use energy to heat water even in the coldest program can be selected.

\subsection{Consumer Appliances in Egypt}

Domestic security issues, especially the bombing of a Russian airliner in October 2015, along with political instability, have had a very negative impact on tourism and foreign investments, which are the key sources of foreign exchange. This has resulted in a shortage of US dollars in the economy, leading to a further decline in international reserves in 2016. Consequently, foreign investments have been withheld and many companies have stopped importing to Egypt which has seen some companies cease production due to a lack of imported goods. US dollar shortages are expected to continue in the short term which will drive inflation rates even higher. Consumer appliances has been negatively affected as most products are fully or partially imported, with an increase in prices and a rather conservative purchasing behavior among consumers [7]. consumer appliances sees varied performance based on product necessity while some categories have faced major changes in their portfolios, other categories have remained stable despite the significant socioeconomic turbulence in 2016. For example, many air treatment products are set to disappear during the forecast period, such as air coolers and room and window air conditioners due to the inconvenience, irrelevance to consumer needs and health issues related to these products. Also, a freestanding fridge faces seriously low demand with these products being rather luxury items that target very niche necessarily. Furthermore; regarding laundry appliances, top loading washing machines is steadily growing due to its convenience in terms of usage and the savings on detergent expenses. Egyptian consumers consider five categories as the most essential in any household; large cooking appliances like freestanding cookers; laundry appliances, be it automatic or semi-automatic washing machines; refrigeration, freestanding fridge freezers; air treatment products, namely cooling fans and vacuum cleaners in a cylinder format [7]. the leading brands offer the most essential consumer appliances , Delving into the five most essential categories in consumer appliances, we find different brands leading different categories. Regarding automatic washing machines, LG and Samsung lead top-loading automatic washing machines while Zanussi leads front-loading washing machines, whereas Toshiba dominates semi-automatic washing machines. Looking at large cooking appliances, we find that Universal and UnionTech lead freestanding large cooking appliances, followed determinately by Grand Roas and Fresh, while Glem Gas and Ariston lead built-in large cooking appliances. As for refrigeration appliances, Kiriazi, Sharp and Toshiba are in the lead followed by LG and Samsung respectively. Regarding air treatment products, Sharp leads air conditioners while Fresh dominates cooling fans. As for vacuum cleaners, Toshiba leads. Based on this it is clear that EIAraby Group has good coverage within the most essential consumer appliances. [7]

\subsection{Distribution channel scene}

An electronics and appliance specialist retailer remains the most important distribution channel for consumer appliances as it offers consumers greater convenience. Internet retailing is steadily emerging in Egypt, with online retailers keen to offer all types of products, although it has been observed that these retailers are more focused on small rather than major appliances. [7]. Consumer appliances are expected to see rather constrained growth due to two main factors. Firstly is the continuous increase in prices which is putting more

IRTIIE Vol. 6, No. 2, 2018 ISSN 1314-8788 (print), ISSN 1314-8796 (online), doi: 10.15547/artte.2018.02.007 
pressure on the limited budgets of Egyptian consumers. Though most consumer appliances' categories are considered to be essential in many households, consumers might find themselves forced to disregard some of them or at least lower their expectations in terms of brand name or features. The other factor is that some of the leading imported brands are ceasing business in Egypt due to the unfavourable legislation regarding imports and duty customs, which will negatively impact the quality and diversity of consumer appliances available in Egypt. And consumers consider a variety of selection criteria when choosing their new laundry appliances. Brand credibility is the main selection criteria and they usually opt for well-known, previously tried brand names which promote confidence in their purchases. They also frequently ask for appliances which have a strong body material, which are stable and which create the least sound during washing. Many consumers have also begun asking for a stainless-steel body Colour. Most sales are for appliances with a washing capacity of $5.5-9.9 \mathrm{~kg}$. After sales service and warranties are also important factors when choosing an appliance. However, price and payment facilities are considered the key factor in terms of influencing the purchasing decision.

\subsection{Competitive Landscape}

Toshiba, LG, Samsung and Zanussi-Electrolux hold the largest volume shares In household washing machines in 2015, in that order. And prospects demand for automatic washing machines will continue to increase during the forecast duration, with high expectations for top-loading automatic washing machines as these appliances are considered the upgrade/innovation within the category. Disclose the latest market trends and reveal future market growth sources for the home washing machine industry in Egypt for local analysts. Look for hidden opportunities in the latest available research data, understand competitive threats through our detailed market analysis, and plan your company's strategy through our qualitative expectations in analysis and growth. If you work in the household laundry industry in Egypt, our article research will save you time and money while enabling you to make informed and profitable decisions. The household washing machine research report in Egypt includes the following:

1. Analyze the procedure that aims to determine the quality of the main supply and demand trends. 2. Detailed division of international and domestic products. 3. Sizes and historical values, company shares and trademark market. 4. Five-year forecasts of market trends and market growth. 5. Strong and transparent research methodology conducted within the country. 6. Our market research reports answer questions such as: What is the size of the household washing machine market in Egypt? What are the major brands in Egypt? What is the average size of washing machines in Egypt? Was there a shift from front loading to upper loading washers? What is the size of automatic washing machines versus semi-automatic washingmachine in Egypt? Why buy this report? 7. Gain competitive intelligence about market leaders. 8. Trace key industry trends, opportunities and threats. 9. Inform your marketing, brand, strategy, market development, sales and logistics functions.

This industrial report comes from the Passport, Consumer Market Research Consumer Database. Population: for five countries: 188.6 Million people/5 persons in family $=37.72$ Million only household washing: Egypt 95.69, Libya 6.423.238, Algeria 40.61, Tunes 11.4, and Morocco 33.848.242.

\subsection{Morocco market for household [11]}

The market for household appliances is carried by essential equipment in renewal (refrigerator, a machine for washing clothes) and complementary purchases (television). The evolution of the equipment trend from 2016 to 2017 remains stable for the TV market. Some products such as stoves, ovens, washing machines have evolved from 1 to $5 \%$. "The market IRTIIE Vol. 6, No. 2, 2018 ISSN 1314-8788 (print), ISSN 1314-8796 (online), doi: 10.15547/artte.2018.02.007 


\section{ARTTIE $Y$}

Ipplied Resseirlohes in Technics, Technologies and Bductation

Journal of the Faculty of Technics and Technologies, Trakia University https://sites.google.com/a/trakia-uni.bg/artte/

for electrical appliances follows the same general trend and is becoming increasingly professional," said the survey, which states that 9 out of 10 purchases are made in department stores and/or independent dealers. The informal sector declined by 6 percentage points compared with 2016, a real proof of reorganization and professionalization of this market. Overall, the 2017 purchasing intentions are slowing down compared to 2016 for all of the products studied. The purchase intention of televisions represents the biggest decrease with 10 points less. Refrigerators and washing machines are also down 2 points each. [11]

\subsection{Moroccans crack for small appliances}

The interest of domestic consumers for automatic and semi-automatic washing machines, washing machine and tumble dryers and dishwashers was confirmed again in 2014: 131,700 washing machines 2014 compared with 127,700 in $2013(+3 \%)$, for a turnover of 522.1 million dirhams $(+1.35 \%)$. Sales of washing machine and dryer handsets rose by $1.6 \%$ to 74,400 units, totaling MAD 440 million. Lastly, while the dishwasher market remained stable between 2009 and 2012, at around 20,000 units, it reached 22,100 units, up 3.3\% compared to 2013, business at constant prices of nearly MAD 73 million.[8]. the main objective of this article is the power and water consumption of automatic washing of each household, which is not affected by the penetration of washing machines in the markets.

However, the total power and water consumption of automatic laundry in the different areas covered by our work seems to be interesting and try in the section "Power and water consumption for automatic laundry by region". The washing machine market in the industrialized countries is saturated, and the North African market is increasingly penetrating. Apart from energy consumption and water in the washing machines, the efficiency of the washing process is determined by the performance of the washing. In some countries where cold washing programs are often used, much water and energy is spent on pre and postwashing treatments as well as washing machine consumption. The power and water consumption of laundry in private homes is determined by the technology of washing machines and also by the number of washings, the selected wash temperature, and the load size even in the washing machine. The washing machine technology is also changing because horizontal washing machine technology is gaining market share in almost all markets in North Africa. But since most markets are already saturated, this will change the inventory of devices only gradually. Laundry habits and practices vary widely in different North African countries and there is little reliable data on actual consumer behavior. Data on water consumption and energy for automatic laundry is incomplete and reliable measurements in use are difficult to obtain. Therefore, some of the data in this report are weak and, in some cases, reasonable guesses must be made; However, this work is the first attempt to clarify the contribution of automatic laundry in the total energy and water consumption of households. The main task of this work is to compare energy consumption and water for laundry by washing machine for energy consumption and total household water. This is done on a country-by-country basis based on available data, but extends to the global picture as much as possible using extrapolations and educated guesses.

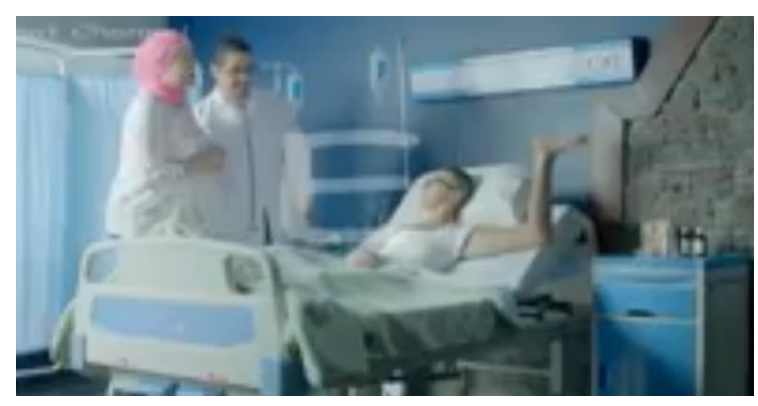

Figure 1. From the picture we find a declaration about the health and repair of laundry washing machine in Egypt. We find in the mother's picture and the Doctor's patient and the patient. The patient replaced his arm with his foot

IRTIIE Vol. 6, No. 2, 2018 ISSN 1314-8788 (print), ISSN 1314-8796 (online), doi: 10.15547/artte.2018.02.007 


\subsection{Problems}

Absence of scientific research on laundry washing technology, the absence of teaching of laundry technology in industrial schools and Egyptian universities (Engineering: Mechanics, Asians, Electronics), (Applied Arts, Textile Technology, Clothing Technology, Printing Technology and Dyeing, Industrial Designs): Using imported technology, with spare parts available, lack of trained technicians for imported types. The use of imported qualities with long time programs that increase the consumption of the following: water consumption; electricity consumption; clothing consumption; consumption of spare parts; consumption of financial resources of the Egyptian family.

\subsection{Lack of Egyptian Customer Service}

The washing machine for laundry in Egypt as customers experience is the Next decade throw competitive battleground and the customer should always be placed at the heart of a business of laundry washing machine, for consumption of clothing, water and energy in Egypt. The current washing machine laundry industry is notoriously terrible at providing quality customer service. This theme is important as customers who are being targeted with these higher incomes by on-demand services will expect a great amount of attention. Due to the large maintenance problem for washing machines and the size of spending the time allocated to advertising channels to compete in the field of maintenance, But there is no specialization except the national companies producing.

\subsection{Objectives}

One way to do this is through a loyalty program or online platform that allows consumers to track their progress and maintain an open channel of communication of laundry washing machine for consumption of clothing, water and energy in Egypt and comparative between national washing machine and forgone industries. Which depends on the payment of water and electricity consumption and spare parts, The default life of the clothes is due to the length of the period and the rates of the package: saving and reducing water consumption; saving and reducing electricity consumption; savings and consumption of clothing; spare parts consumption; providing employment opportunities for young graduates; provision of professional training for technicians in accordance with different types; provide parts in the curricula of specialized colleges and institutes; provision and allocation of laboratories for scientific research and training in home and specialized processing technology; provision and Consumption of financial resources of the Egyptian family.

Because there is no apartment in Egypt and contain only at least a washing machine for clothes.

\section{MATERIAL AND METHODS}

Materials and equipment's: According to the Egyptian market survey, a 100\% plain-weave cotton fabric with density of $25 \times 15$ (wrap $\times$ weft $/ \mathrm{cm}$ ), mass per unit area of $140 \mathrm{~g} / \mathrm{m}^{2}$ and plain weave construction was purchased from Miser spinning and weaving company, (Mahala Elkoubra Egypt) and were chosen as test samples as the flowing in Table 1.

Table 1. Specification of fabrics properties of test samples

\begin{tabular}{|c|c|c|c|c|c|c|c|}
\hline \multirow[t]{2}{*}{ Material } & \multirow[t]{2}{*}{ Weave } & \multirow{2}{*}{$\begin{array}{l}\text { Size } \\
(\mathrm{cm} \times \mathrm{cm})\end{array}$} & \multirow{2}{*}{$\begin{array}{l}\text { Count } \\
\text { (Tex) }\end{array}$} & \multicolumn{2}{|c|}{ Density (yarns/cm) } & \multirow{2}{*}{$\begin{array}{l}\text { Weight } \\
\left(\mathrm{g} / \mathrm{cm}^{2}\right)\end{array}$} & \multirow{2}{*}{$\begin{array}{l}\text { Thickness } \\
(\mathrm{mm})\end{array}$} \\
\hline & & & & Warp & Weft & & \\
\hline Cotton $100 \%$ & Plain & $40 \mathrm{~cm} \times 40 \mathrm{~cm}$ & 33.8 & 25 & 15 & 20 & 0.79 \\
\hline
\end{tabular}

According to AATCC $124: 2010$, test samples are cut into approximately $40 \mathrm{~cm} \times 40 \mathrm{~cm}$ squares. Moreover, in order to achieve a specified filling load in a drum washer, cotton pillowcases, mentioned in Toshiba $8 \mathrm{~kg}$ and Hoover $5.5 \mathrm{~kg}$. Clothes washing machines for

IRTIIE Vol. 6, No. 2, 2018 ISSN 1314-8788 (print), ISSN 1314-8796 (online), doi: 10.15547/artte.2018.02.007 


\section{ARTTIE $Y$}

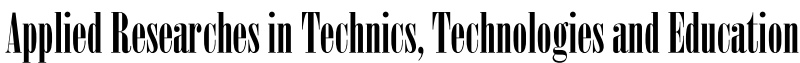

Journal of the Faculty of Technics and Technologies, Trakia University https://sites.google.com/a/trakia-uni.bg/artte/

household use the detailed information about test samples and wash load are presented in Tables 1 and 2 respectively. Additionally, test samples were washed with ordinary detergent solution followed By ordinary tap water and drying at room temperature in order to eliminate the resulting strain in the production process and all samples were conditioned at 20D and $60 \% \mathrm{RH}$ for at least 24 hours. the washing parameters were selected relating to mechanical force and the four key influencing factors are wash load size, washing rotating speed, water volume and spinning speed, Water temperature was not considered. Temperature could influence the viscosity of the wash medium, while the change of the viscosity of wash medium is not significant on mechanical action. The factor of experimental design, wash load size was determined the major influencing factors for cotton fabric smoothness appearance (grade). Then we studied and analyzed the relationships between wash load size, fabric washing time (min) and smoothness appearance (grade). The detailed information about single experiment is shown in Table 2.

The specimens were line-dried under standard atmospheric conditions for 4-12 hours. And three trained observers rated the fabrics independently based on AATCC 124:2010. Softness appearance of fabrics after washing repeated houses in a uniform inspection booth.

Table 2. Washing procedures with different load size

\begin{tabular}{|l|l|l|l|l|l|l|l|}
\hline $\begin{array}{l}\text { Washing } \\
\text { machines }\end{array}$ & $\begin{array}{l}\mathrm{t} \\
\left({ }^{\circ} \mathrm{C}\right)\end{array}$ & $\begin{array}{l}\text { Load } \\
\text { Size } \\
(\mathrm{Kg})\end{array}$ & $\begin{array}{l}\text { Water } \\
\text { Volume } \\
(\mathrm{L})\end{array}$ & $\begin{array}{l}\text { Washing } \\
\text { time } \\
(\mathrm{min})\end{array}$ & $\begin{array}{l}\text { Spinning } \\
\text { Speed } \\
(\mathrm{rpm})\end{array}$ & $\begin{array}{l}\text { Smoothness } \\
\text { Appearance } \\
\text { (grade) }\end{array}$ & $\begin{array}{l}\text { Standard } \\
\text { deviation }\end{array}$ \\
\hline Toshiba $8 \mathrm{~kg}$ & 30 & 1 & 8 & 60 & 800 & 2.0 & 0.1 \\
\hline Hoover $5.5 \mathrm{~kg}$ & 30 & 3 & 24 & 150 & 800 & 1.7 & 0.32 \\
\hline
\end{tabular}

However the estimated power and water consumption of the residential sector is often deployed by the national statistical office of the country. It is often difficult to obtain accurate data on energy consumption and water for laundry by washing machine. The energy efficiency of washing machines is the focus of many systems locally or regionally. Within 10 years, improvements in energy and water efficiency were revealed by $30 \%$ in horizontal axis technology for North Africa. At present, all washing machines sold in Africa belong at least to the category of energy cards are undoubtedly due to the policy of forced energy efficiency in the North African region. [14, 4], therefore, the actual water consumption and energy of each washing cycle depends to a large extent on the life of the washing machine. Accurate data are not available for use in all countries. Due to significant differences in actual consumption measured for each wash cycle, disaggregated values should not be used. In order to fill the data gaps, some reasonable assumptions had to be made, but for some countries, the share of water consumption for washing was uncertain. These are clear signs in the report in five countries, In North Africa Egypt, Libya, Tunisia, Algeria and Morocco are included in our calculations. Number of wash cycles per household The consumption of energy and water for laundry by washing requires information on the returns and practices of washing, such as the number of wash cycles per year, the selected wash temperature, and the average size. Only a small amount of data is available regarding the actual wash that has been washed for each wash cycle. According to a recent study conducted in Egyptian households, the load sizes of each wash cycle increased with the increase in the size of households. In North Africa, it was observed that most households always use the washing machine with more than $65 \%$ of their capacity to provide more detailed information on the actual sizes of each wash cycle in water consumption per household. It can be assumed that the total number of wash cycles increases with the increase in the number of people living in the home, while the number of purposes per person living in the household decreases with the size of households.

This was measured by the total energy consumption of laundry in household washing machines for samples in one week to $145 \mathrm{kWh}$ and the average consumption per cycle at

IRTIIE Vol. 6, No. 2, 2018 ISSN 1314-8788 (print), ISSN 1314-8796 (online), doi: 10.15547/artte.2018.02.007 


\section{AR'IIE ( Ipplied Researthes in Technics, Technologies and Bduration Journal of the Faculty of Technics and Technologies, Trakia University https://sites.google.com/a/trakia-uni.bg/artte/}

$0.91 \mathrm{kWh}$ (average load, 5.5 and $8 \mathrm{~kg}$, imported washing machine). This takes one week, resulting in an annual energy consumption of $145 \mathrm{kWh}$ and 160 wash cycles per household. It is clear that the number of wash cycles per family per week; Egypt, Libya, Tunisia, Algeria and Morocco are running more laundry cycles. This seems to be associated with repeated use of cold and hot washing programs.

However, cold and hot washing is widespread in Egypt and Morocco, and in both countries, the number of wash cycles per family per week is relatively low. While there is still an explanation for Egypt, the decline in the number of wash cycles in Egypt is due to repeated hand washing of clothes despite the availability of a washing machine. The leading country with regard to the number of wash cycles with about 10 loads per week is Egypt, which is clearly due to the common use of very short and cold washing programs and relatively low load size. In terms of energy use in the Egyptian housing sector 2010-2010 wash cycles per year, while statistics indicate that about $65 \%$ of Egyptian households manage five wash cycles or less per week. Due to the decrease in house sizes and the increase in the number of horizontal axis devices in the Egyptian market, it seems reasonable to estimate five wash cycles per week (280 cycles per year). According to the REMODECE report, about $50 \%$ of washing machines in North African households are less than 5 years old, 30\% are between 6 and 10 years old and $20 \%$ are over 10 years old (de Almeida et al. 2007). Therefore, it seems to be fair to use the average energy consumption per wash cycle published by IBM in 2002. For some North Africa countries, mainly the New Member States, no specific information is available; therefore, an energy consumption of $0.97 \mathrm{kWh}$. [3]

Figure 2 shows washing machine brand of "Toshiba" $8 \mathrm{KG}$ Automatic. White color and top Loading AEW-8460SP: Water amount: High level: 48 Liters, Low level: 23 Liters. Cycles: Regular cycle, Soak cycle: Up to 60 minutes, Heavy wash, Delicate cycle, Speed program. Water consumption: High level: 129 Liters, Rated period of operation: Regular cycle 75 min. Wash: Pulsator diameter: $\varphi 334 \mathrm{~mm}$ (2layers), Revolution: $50 \mathrm{~Hz}(145 \mathrm{rpm}),(\mathrm{rpm}): 60 \mathrm{~Hz}$ (174rpm), Loading Q'ty: 40ft:160sets. Washing machine dimensions (mm): Height $x$ Width $x$ Depth: 920 x 535 x 536 , Body color: White , Warranty: 5 Years full free warranty.

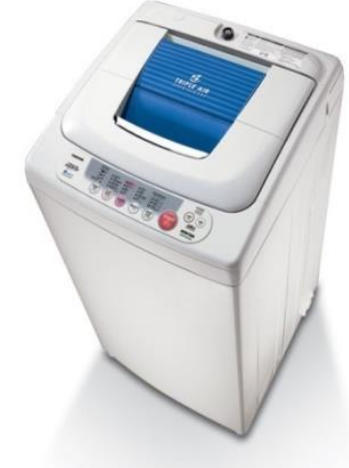

Figure 2. Washing Machine "Toshiba" 8KG Automatic. Top Loading AEW-8460SP

\subsection{Water consumption per household}

The average volume of water consumption in the wash cycle is based mainly on the washing machine technology. Vertical axis devices consume about twice as much as horizontal machines in the wash cycle. Modern washing machines with horizontal axis technology are often characterized by automatic load sensing function to reduce water and energy consumption in response to consumer loads below the estimated capacity. Most vertical axis devices also include water level settings automatically or the water level can be manually set by the user. Although to date there has been no systematic evaluation of partial load performance, the availability of the function may lead to the expectation that the actual water consumption per wash cycle is significantly lower than the estimated value provided that the

IRTIIE Vol. 6, No. 2, 2018 ISSN 1314-8788 (print), ISSN 1314-8796 (online), doi: 10.15547/artte.2018.02.007 


\section{ART'TE $Y$}

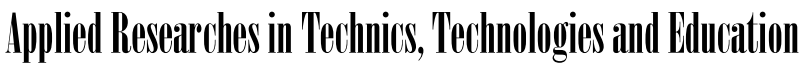

Journal of the Faculty of Technics and Technologies, Trakia University https://sites.google.com/a/trakia-uni.bg/artte/

consumer does not use the full capacity of the washing machine. Laundry 1,265 cycles [2] , Obviously, for white and colored clothes with hot wash programs, the capacity of the washing machine is not fully used, while the load sizes are quite large for easy care and delicates which are washed with warm or cold water temperatures. A survey on the Egypt laundry market published reports water level settings of 4,142 wash cycles in Africa $n$ households. Load diary data show that more than $50 \%$ of the courses were run at a very large and large water level, about $40 \%$ of the washings were done with a medium / normal water level, and only $18 \%$ with low water levels. The low additional options and the mini basket were not used at all. These observations show only consumer behavior in Egypt, Libya and Morocco, behavior may be in different countries. But it is clearly too early to emphasize that washing machines use less water frequently than low-load loads or low water levels.

\section{RESULTS AND DISCUSSIONS}

In Egypt when increasing washing rotating speed, spinning speed and water volume, the grade of smoothness appearance varied only lightly, which indicated that these factors has a minor influence on wrinkling of cotton fabrics in a front loading washer. Egyptian Cotton Fabric movements are more complex with sliding, falling, tumbling and rotating in a drum washer. whichever rotating speed it is, fabrics will experience all the movement modes mentioned above with our experimental condition and the external force imposed on cotton fabric may be similar. subsequently the smoothness appearance of cotton fabrics varied lightly with different speed. The amorphous region in cotton fiber consists of approximately 46.1-49.7\%, where large amount of hydrophilic groups exists.

Water molecules bind to water-loving groups in the non-crystalline region that absorb them once in the non-crystallized region, thus facilitating the transport of molecules, resulting in easy recovery and wrinkles. The test results were used to examine the important factors influencing the appearance of tissue softness, and the size of the washing load was found to be important in distinguishing the softness appearance of a $94 \%$ confidence scout of 0.031 . In five countries in North Africa: (Egypt, Libya, Algeria, Tunisia and Morocco). Thus, the relationship between fabrics movement and wrinkles with the size of the wash load was examined. With the increase in washing load, the degree of softness is reduced from 2.0 to 1.4 , indicating that the size of the washing load affects the performance of wrinkles of the lumbar tissue significantly. This may occur by reducing the motion area of the fabric in the fixed internal cylinder. Moreover, the difference was also caused by the complicated mechanical work displayed on the fabrics including shear stress and stress / stress stress. A previous study showed that the speed of washing and spinning increased the amount of wrinkles due to the relative movement of fabrics and fluids in the overhead washing machine. The reason may be that the volume of water has no significant impact on the appearance of smooth cotton fabric. In conclusion, the unexpected permanent deformities of the clothe are wrinkles as crinkles, by Microcosmic mechanism wrinkling of crinkles prove that the wrinkles are plastic deformation of wrinkles due to friction, but fail to return to its original position after the removal of strength or pregnancy, Both fibrous or histological structure of fabrics and mechanical forces have a significant impact on the degree of wrinkles, energy consumption of automatic laundry for each household. The energy consumption of laundry is mainly dependent on the average washing temperature. Throw the choice between alternatives lowtemperature household washing or high-temperature washing programs depend on one of the technical parameters of the washing machine and power supply, on the other hand, depends on the traditional washing practices and practices in the area concerned, the large differences in the energy consumption of each wash cycle. The best cleaning performance needs to have minimal input energy, It is mechanical work, thermal energy, chemicals, time. This may include warm water from the tap and hence the energy of external resources that can not be measured. Because of the size of the larger family and consequently the increase

IRTIIE Vol. 6, No. 2, 2018 ISSN 1314-8788 (print), ISSN 1314-8796 (online), doi: 10.15547/artte.2018.02.007 


\section{ART'TE $Y$}

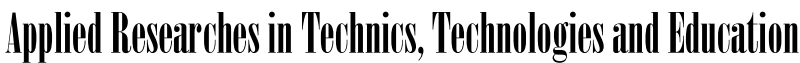

Journal of the Faculty of Technics and Technologies, Trakia University https://sites.google.com/a/trakia-uni.bg/artte/

in the number of wash cycles in North African countries (Egypt, Libya, Algeria, Tunisia and Morocco), energy consumption is slightly higher than that of North Africa and converted to $\mathrm{kWh}$ per year and household. This corresponds to calculated consumption of 88.4 kilowatt hours . Compared to the energy consumption of laundry by total energy consumption, it becomes clear that only a small fraction of the private household energy bill is due to the washing machine, which is the average of North Africa (Egypt, Libya, Algeria, Tunisia and Morocco). The household has the highest total energy consumption among the countries studied, Between total energy consumption and energy consumption of laundry is more pronounced in terms of shares expressed as a percentage, and the difference in the share between North Africa (3.7\%) and North Africa (8.2\%) due to lower energy consumption of North African households. expected at the relatively high energy consumption of laundry and low total energy consumption of only $1.7 \mathrm{MWh}$ per household, based on our account, and North Africa (Egypt, Libya, Algeria, Tunisia and Morocco), the share of washing washing is about $1 \%$ of the total energy bill. $[9,10]$, the high market penetration of integrated heating axles in these countries may increase the share of automatic washing in the near future, especially in countries with energy and savings projects will be implemented to reduce total household energy consumption. In addition to energy consumption for laundry, water consumption is affected by the technical standard of the washing machine and the user behavior, for example, the number of weekly wash cycles. This constellation accounts for a $16.8 \%$ increase. North Africa (Egypt, Libya, Algeria, Tunisia and Morocco) uses less-thanwater washers for each wash cycle compared to washing machines in Africa, Because of the economic consumption of water for washing machines in North Africa, which can not be counted as potable water but as water used for laundry. With regard to the total water consumption of households, the large differences between the different countries The percentage of water consumption in laundry washing between $5 \%$ and $19 \%$ and depends on the consumption of water for each wash cycle and the total water consumption of the family. The volume of water used for laundry affects the total water consumption of households in all countries significantly. The relationship between total household water consumption and water consumption for washing is more pronounced in terms of shares expressed as a percentage. The increasing market share of horizontal axis machines in North Africa (Egypt, Libya, Algeria, Tunisia and Morocco), Will likely reduce the consumption of water for automatic laundry in the near future. Automatic power and water consumption for automatic laundry By region With the collected data, the contribution of the consumed resources for automated laundry can not be estimated only to the total energy and water bill for one individual but also the total amount of energy and water consumed for automatic laundry in the areas surveyed in our report. About the total number of households that have a washing machine and the consumption of energy and water for automatic laundry in different areas and the total. Taking into consideration the rate of ownership, this covers approximately $780,000,000$ households with about 2.3 billion people living in the areas listed in this report, which represents about one third of the population of North Africa (Egypt, Libya, Algeria, Tunisia and Morocco). Enargy consumption and water in the universal washing machine may be in the maximum height twice (about 100 watts per hour and $20 \mathrm{~km} 3=20,000,000,000 \mathrm{~m}^{3}$ of water), as in most countries outside laundry washing is still being investigated manually.

\section{CONCLUSION}

The analysis of fabric movement during drum washer washing illustrated that the higher the washing loading is, the smaller free motion region and the more the number of tumbles will be, resulting more complex mechanical action imposing on fabrics due to shear forces or tension/compression stress from adjacent textiles or even the drum, By summarizing the results, one can say that there are significant differences in energy and water consumption for automatic laundry. The reasons for these differences are the different numbers of wash

IRTIIE Vol. 6, No. 2, 2018 ISSN 1314-8788 (print), ISSN 1314-8796 (online), doi: 10.15547/artte.2018.02.007 
cycles per year, different wash temperatures, and different techniques such as horizontal and vertical washing machines for the axis. Estimating the amount of energy and water is difficult as traditional washing habits and practices differ from a large number of households. For example, you need more water to wash clothes than any other country, but not only the drinking water used and the amount of reused water from the bathroom remains unknown. Households in North Africa consume much less water. Water consumption for laundry ranges between $5 \%$ and $19 \%$ depending on the water consumption of each wash cycle and the total water consumption of the household.

The volume of water used for laundry affects the total water consumption of households in all countries significantly. The relationship between total household water consumption and water consumption for washing is more pronounced in terms of shares expressed as a percentage. Total number of households owning washing machine and energy and water consumption for automatic laundry in different and total areas. Taking into account the rate of ownership, this covers approximately $780,000,000$ households with about 2.3 million people living in the areas listed in this report. It is difficult to quantify the amount of energy and water inputs where traditional washing habits and practices are very different. For example, households need more water for washing than any other country, but only drinking water is used, and the amount of reused water from the bathroom is still unknown.

\section{REFERENCES}

[1] Australian Bureau of Statistics. (2008). Environmental issues: Energy use and conservation. Canberra: Australian Bureau of Statistics.

[2] Berkholz P., Stamminger R., Kruschwitz A. \& Brückner A. (2006). Definition und Ermittlung verhaltensabhängiger Energiesparpotentiale beim Betrieb elektrischer Haushaltswaschmaschinen. Bonn.

[3] de Almeida A., et al. (2007). Residential monitoring to decrease energy use and carbon emissions in Europe. Portugal: ISRUniversity of Coimbra, Dep. Electrical Engineering.

[4] DEWHA. (2008a). Equipment energy efficiency program. Australia: Department of the Environment, Water, Heritage and the Arts.

[5] DEWHA. (2008b). Energy use in the residential sector 1986-2020. Australia: Department of the Environment, Water, Heritage and the Arts.

[6] DEWHA. (2008c). Energy use in the residential sector 1986-2020. Australia: Department of the Environment, Water, Heritage and the Arts.

[7] Euromonitor International. (2012). Making sense of global markets: Consumer Appliances in Egypt. http://www.euromonitor.com/consumer-appliances-in-egypt/report.

[8] Euromonitor International. (2017). Making sense of global markets: Moroccans crack for small appliances. http://www.euromonitor.com/consumer-appliances-in-morocco/report.

[9] Eurostat. (2006a). Table nrg 105a energy. http://epp.eurostat.ec.europa.eu/tgm/table.do?tab=table\&init=1\&language=de \&pcode=te n00101\&plugin $=1$.

[10] Eurostat. (2006b). Table env_watq3 water. http://epp.eurostat.ec.europa.eu/tgm/table.

[11] http://lavieeco.com/news/actualite-maroc/92-des-menages-au-maroc-ont-au-moins-unetele-38-ont-une-machine-a-laver-22948.html.

[12] https://www.elarabygroup.com/en/home. Retrieve at: 1 march 2015.

[13] Nakaoka K., \& Sudarsana B. S. (2002). Laundry in Japan. Procter \& Gamble communication to IEC SC59D working groups (private communication).

[14] US Federal Register. (2015). Retrieved January 2008. http:// frwebgate6.access.gpo.gov/cgi-bin/TEXTgate.cgi?WAISdoc

$D=659635452204+20+1+0 \&$ WAISaction=retrieve.

IRTIIE Vol. 6, No. 2, 2018 ISSN 1314-8788 (print), ISSN 1314-8796 (online), doi: 10.15547/artte.2018.02.007 